\title{
RANCANGBANGUN RANGKAIAN INVERTER SPWM UNIPOLAR 1 FASA DENGAN PENGATURAN FREKUENSI OUTPUT
}

\author{
Fathoni $^{1}$, Agus Pracoyo ${ }^{2}$, Totok Winarno ${ }^{3}$, Rizal Sabillah ${ }^{4}$ \\ 1,2,3 Jurusan Teknik Elektro Politeknik Negeri Malang \\ $\left.{ }^{4}\right)$ Mahasiswa Program D4 Politeknik Negeri Malang \\ pakfapyrus@yahoo.com
}

(Artikel diterima: Oktober 2019, direvisi: September 2019, diterima untuk terbit: Januari 2020)

\begin{abstract}
Changing the de sgnal to ac signal is done for te purpose of load regulations, such as the ac motor speed, heater and lamp. Inverter work is done by ac rectification first and then converted again to a 1 phase ac signal. The ac output signal is a sinosoidal PWM (SPWM) type of unipolar 220 volts from the input 24 volt de voltage. Unipolar SPWM signal generation is done by a microcontroller with programming. The number of counts (resolutions) of the SPWM signal and the period are set from the amount in the register, can be set to 8 bits or other constants. The power part of the SPWM inverter is the N channel MOSFET bridge circuit H with IR2110 solid state driver. Step transformer as a load while step-up the inverter output voltage. Determination of the output frequency is set through a rotary encoder that can be adjusted up (increment) or down (decrement). There are 5 frequency variations, namely 30, 40, 50, 60 and $70 \mathrm{~Hz}$. To get the inverter efficiency, the type of MOSFET used is chosen to have the type that has a low RDS (on) value and the right driving pulse, according to the switch configuration. Measurement of the output frequency is done by reading the image on the osciloscope. The observations show a frequency value that is almost the same as the constant. The test results show the difference in output voltage which is reduced at a 30 watt load.
\end{abstract}

Kata kunci: Inverter, H bridge, SPWM, frequency, output voltage

\section{Pendahuluan}

Inverter adalah rangkaian pengubah besaran dc menjadi ac. Input inverter dapat menerapkan gelombang sinus, kotak, modifikasi sinus serta sinusiodal pulse width modulation (SPWM). Terdapat 2 macam sinyal SPWM yaitu, bipolar dan unipolar. Pembentukan sinyal SPWM jenis bipolar maupun unipolar memerlukan 2 buah atau 3 buah pembangkit sinyal. Gelombang segitiga sebagai acuan perioda pulsa sedangkan gelombang sinus sebagai pengubah lebar pulsa dan perioda sinyal outputnya. Pada pembentukan bipolar SPWM diperlukan satu buah gelombang sinus sedangkan pada pembentukan unipolar SPWM diperlukan 2 buah gelombang sinus dengan frekuensi yang sama tetapi berbalikan polaritasnya. Artikel dari Anuja N, Harshal S.Wani (2014) dalam "Bipolar and Unipolar Inverter" menjelaskan kronologi pembentukan sinyal SPWM unipolar untuk inverter untuk rangkaian $\mathrm{H}$ bridge. Penelitian dilakukan dengan program Matlab dan Simulink. Gelombang SPWM digunakan sebagai penggerak MOSFET maupun IGBT dalam rangkaian $\mathrm{H}$ bridge. Bentuk gelombang SPWM dan pembentukannya ditunjukkan dalam Gambar 1.[1]

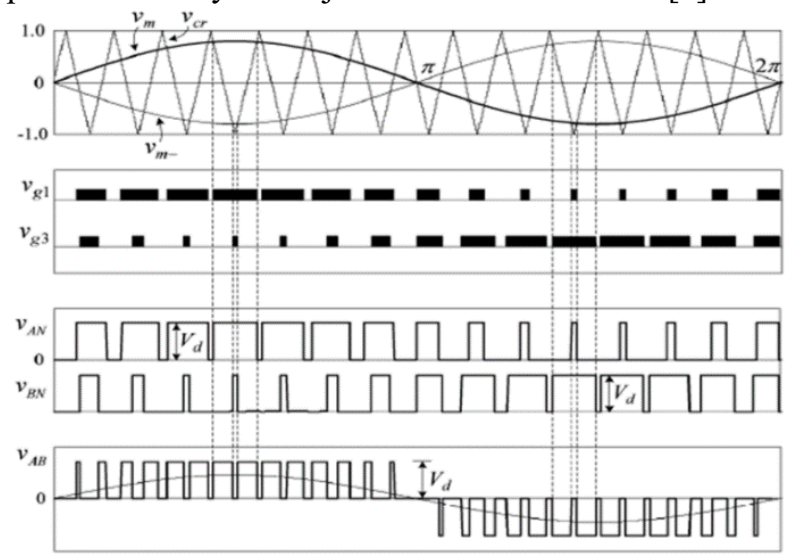

Gambar 1. Pembentukan SPWM
Bagian penguat daya pada inverter gelombang SPWM menggunakan rangkaian $\mathrm{H}$ bridge yang merupakan rangkaian 4 buah saklar semikonduktor seperti terlihat dalam Gambar 2. Prinsip kerja rangkaian saklar adalah hantar berbarengan untuk pasangan silang atau diagonal. Input 1 akan menggerakkan S1 dan S4 sedangkan input 2 akan menggerakkan S2 dan S3. Dengan cara tersebut maka polaritas di titik A dan B akan selalu berbalikan. Pada terapan inverter dengan input SPWM unipolar, pasangan saklar S1 dan S4 bekerja pada setengah perioda sinus positip sedangkan pasangan saklar S2 dan S3 bekerja untuk setengah perioda negatip.

Saklar dapat dibangun dari BJT, MOSFET maupun IGBT. Penggunaan jenis semikondutor BJT memerlukan rangkaian penggerak yang berbeda terhadap penggunaan MOSFET dan IGBT. Jenis kanal serta type semikonduktor dalam rangkaian $\mathrm{H}$ bridge juga menjadikan perbedaan konfigurasi penguat sisi atas terhadap sisi bawah serta keadaan atau level dari sinyal penggeraknya.

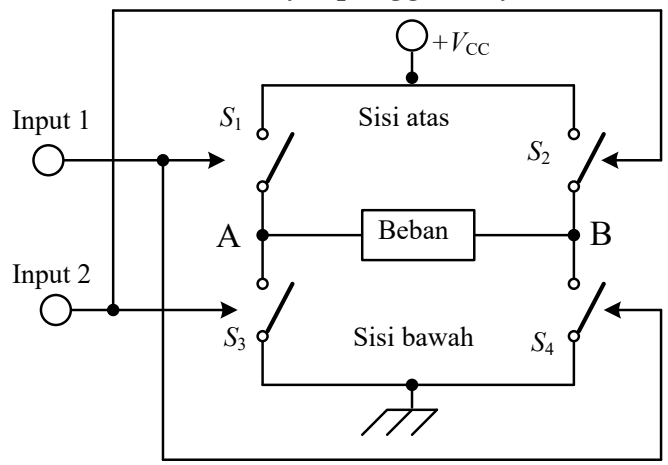

Gambar 2. Rangkaian inverter

Saklar yang digunakan dalam rangkaian $H$ bridge dapat berupa BJT, MOSFET maupun IGBT. Rangkaian penggerak atau driver untuk jenis saklar semikonduktor bisa berbeda dan tergantung dari besaran tegangan maupun arus yang diperlukan. Penggunaan MOSFET kanal N pada sisi atas 
maupun bawah menjadikan konfigurasi yang berbeda. Sisi atas konfiguasi common drain (CD) sedangkan sisi bawah konfigurasi common source (CS). Walaupun kedua sisi mempunyai konfigurasi berbeda tetapi sama untuk penggerak aktif tinggi. Perbedaan konfigurasi tersebut menjadikan kebutuhan amplitudo pulsa input sebagai penggerak menjadi berbeda. MOSFET dengan konfigurasi CD memerlukan amplitudo yang lebih tinggi dibanding pulsa penggerak konfigurasi CS.[2]

\section{Tinjauan Pustaka}

\section{A. Inverter SPWM Unipolar}

Gelombang SPWM yang digunakan sebagai input rangkaian $H$ bridge adalah jenis unipolar. Pembangkitan gelombang SPWM unipolar dapat dilakukan secara diskrete maupun dengan program. Yohan Fajar Sidik, F. Danang Wijaya dan Eka Firmansyah (2013) dalam paper penelitiannya yang berjudul Sinusoidal Pulse Width Modulation Berbasis Lookup Table Untuk Inverter Satu Fase Menggunakan 16-Bit Digital Signal Controller menjelaskan bahwa inverter yang dibuat pada penelitian ini menggunakan topologi switching full bridge. Unipolar SPWM dibentuk dari perbandingan antara dua buah sinyal referensi yang berbeda fase sebesar $180^{\circ}$ dengan sebuah sinyal pembawa. Sinyal referensi berupa sinyal sinus dan sinyal pembawa berupa sinyal segitiga. Pada perancangan sine lookup table tetap menggunakan perbandingan antara sinyal referensi dengan sinyal pembawa. Sinyal pembawa dalam mikrokontroller adalah sistem pewaktuan PWM. Sinyal pewaktuan dalam dsPIC30F4012 dapat dipilih dalam mode cacah naik dan cacah turun dalam satu perioda. Sedangkan sinyal referensi dapat dibentuk dengan bantuan perangkat lunak PSIM untuk membentuk lebar-lebar pulsa dalam satu perioda sinus yang kemudian disimpan dalam variabel array. Mikrokontroller dsPIC30F4012 ini memiliki 3 buah pasang modul PWM, namun pada penelitian ini hanya digunakan 2 modul karena sinyal yang dibangkitkan berjumlah empat, yaitu sinyal $S_{1}, S_{2}$, $S_{3}$ dan $S_{4}$. Proses pembentukan kedua buah sinyal tersebut adalah dengan mengaktifkan mode complementary, yang secara otomatis akan menghasilkan keluaran PWM yang saling berkomplemen. Fitur menarik lainnya dalam dsPIC30F4012 adalah dapat disisipkan nilai dead time pada sinyal dengan mode complementary. [3]

Sinyal SPWM dapat dibangkitkan menggunakan mikrokontroller. Cara ini adalah cara yang paling sederhana secara hardware karena didukung dengan software . Dengan demikian kerumitan hardware dikompensasi oleh software yang secara fisik akan mengurangi dimensi dan penyerapan daya. Pembangkitan sinyal PWM ini, mikrokontroller ATMEL ATmega menggunakan mode phase correct PWM yaitu sinyal termodulasi berbentuk segitiga seperti terlihat dalam Gambar 3.

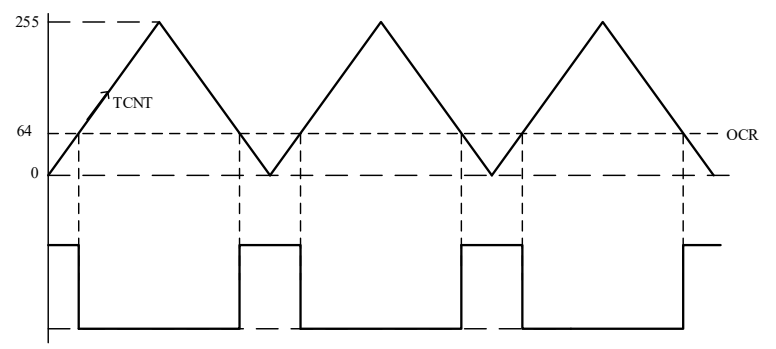

Gambar 3. Pembentukan pwm pada atmega16

Pembentukan gelombang SPWM oleh mikrokontroller
Atmega16 dilakukan dengan pencacahan setengah gelombang sinus, mengubah ke bilangan hexadecimal dan disimpan dalam reister OCR. Program akan membaca tabel loocked up table. Pada inverter SPWM dengan gelombang unipolar, setengah perioda gelombang positip digunakan untuk setengah perioda gelombang negatip pada kerja pasangan saklar berikutnya dalam rangkaian $H$ bridge. Setengah perioda gelombang sinus $\left(180^{\circ}\right)$ dicacah menjadi beberapa pulsa. Jumlah cacahan diatur dari program. Variasi amplitudo gelombang sinus diubah menjadi variasi lebar pulsa. Pulsa dengan duty cycle tertinggi pada sudut mendekati $90^{\circ}$. Prinsip Prinsip kerja pencacahan dapat dilihat dari Gambar 4. Duty cycle dari SPWM adalah proporsional terhadap amplitudo cacahan. Amplitudo cacahan ditabelkan dan dibaca untuk pembangkitan SPWM.[4]

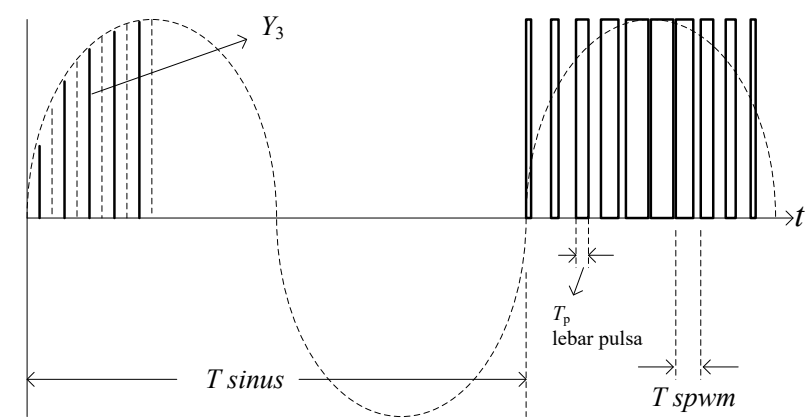

Gambar 4. Pencacahan gelombang sinus

\section{B. Rangkaian H bridge}

Rangkaian $H$ bridge dapat dibangun dari MOSFET jenis kanal sama ataupun komplemen atau campuran. Jika digunakan kanal yang sama, konfigurasi sisi atas dan bawah menjadi berbeda sedangkan jika digunakan MOSFET komplemen konfigurasi sisi atas akan sama dengan sisi bawahnya. Macam konfigurasi akan mempengaruhi kondisi aktif serta amplitudo pulsa pemicunya. Penggunaan kanal $\mathrm{N}$ seragam untuk sisi atas dan bawah menjadikan konfigurasi yang berbalikan. Sisi atas sebagai common drain (CD) sedangkan sisi bawah adalah common source (CS). Kedua konfigurasi bersifat aktif tinggi tetapi kebutuhan amplitudo pulsa tidaklah sama. Beban sisi bawah ada pada drain sedangkan beban sisi atas ada pada source.

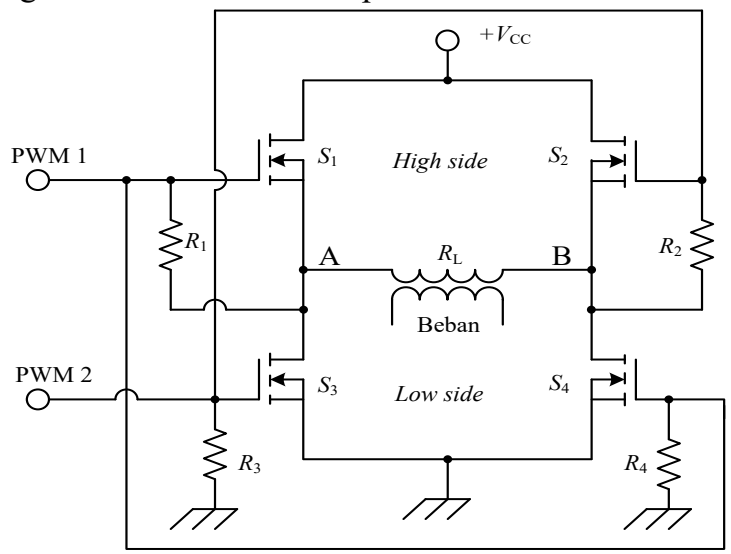

Gambar 5. Rangkaian h bridge mosfet

Beban rangkaian $H$ bridge bisa merupakan beban inverter jika tegangan sumber rangkaian adalah tegangan tinggi yang sama dengan nilai tegangan output yang 
direncanakan. Beban bisa berupa trafo step up jika tegangan sumber rangkaian adalah tegangan rendah.

\section{Rangkaian Penggerak MOSFET}

Penggunaan MOSFET jenis kanal $\mathrm{N}$ pada rangkaian $H$ bridge memerlukan rangkaian penggerak khusus karena konfigurasi yang tidak sama. Penempatan beban menjadikan amplitudo tegangan input konfigurasi $\mathrm{CD}$ lebih tinggi dibanding konfgurasi CS. Pada konfigurasi CS amplitudo tegangan input adalah sama atau lebh tinggi dari tegangan gate-source threshold sedangkan untuk konfgurasi $\mathrm{CD}$ amplitudo tegangan input harus lebih tinggi dari $V_{\mathrm{GS}(\mathrm{th})}$ ditambah tegangan beban $\left(V_{\mathrm{RL}}\right)$. Batas tegangan gate-source dapat dilihat pada lembar data komponen yang digunakan.

$$
\begin{aligned}
& V_{\mathrm{IN}(\mathrm{CS})} \geq V_{\mathrm{GS}(\mathrm{th})} \\
& V_{\mathrm{IN}(\mathrm{CD})} \geq V_{\mathrm{RL}}+V_{\mathrm{GS}(\mathrm{th})}
\end{aligned}
$$

Jika tegangan beban hampir sama dengan $V_{\mathrm{CC}}$ maka

$$
V_{\mathrm{IN}(\mathrm{CD})} \geq V_{\mathrm{CC}}+V_{\mathrm{GS}(\mathrm{th})}
$$

Pada terapan dari pembangkit SPWM mikrokontroller, pulsa SPWM mempunyai amplitudo hampir 5 volt sehingga untuk penggerak MOSFET sisi atas diperlukan rangkaian penaik tegangan yang dapat berupa rangkaian penguat tegangan dengan amplitudo catu daya yang cukup, pengganda tegangan atau gabungan keduanya. Umumnya ditambahkan kopling cahaya sebagai isolator sistem catu daya antara pembangkit pulsa dan penguat daya.

Salah satu rangkaian penggerak MOSFET jenis solid state untuk keperluan $\mathrm{H}$ bridge kanal $\mathrm{N}$ (konfigurasi CD pada sisi atas dan CS pada sisi bawah) adalah IR2110. Diperlukan 2 nilai tegangan catu daya, 5 dan 12 volt. Rangkaian berisi kopling cahaya dan pengganda tegangan. Rangkaian penggerak IR2110 juga telah dilengkapi dead time secara internal. Rangkaian pengganda tegangan dilakukan dengan komponen dioda dan kapasitor pada output $V_{\mathrm{B}}$ (tegangan bootstrap). Skema rangkaian penggerak MOSFET IR2110 ditunjukkan dalam Gambar 6. Dioda yang digunakan adalah dioda switching dengan kemampuan arus yang cukup. $D_{2}$ dan $D_{3}$ digunakan untuk mempercepat pengosongan kapasitor gate.[5]

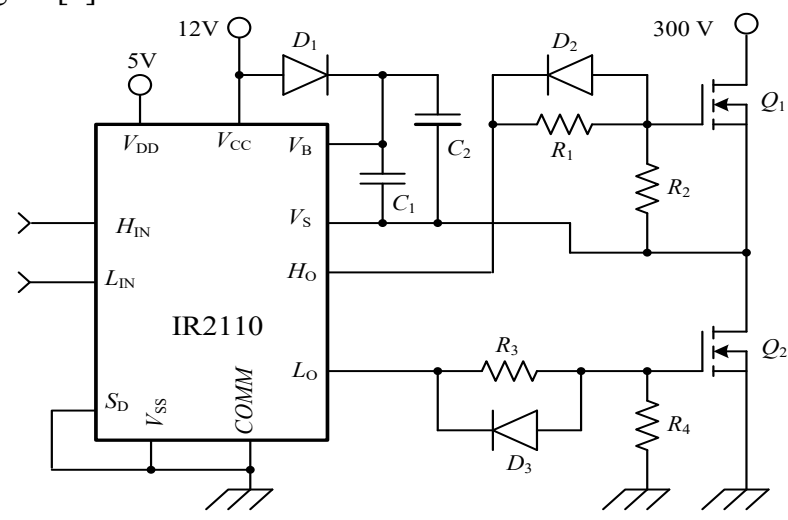

Gambar 6. Skema driver mosfet dasar

\section{Metodologi Penelitan}

\section{A. Diagram Blok Sistem}

Diagram blok rangkaian inverter dengan pengaturan frekuensi output ditunjukkan dalam Gambar 7.

Terdapat 3 test point (TP) untuk pengamatan bentuk gelombang saat digunakan sebagai modul praktikum.

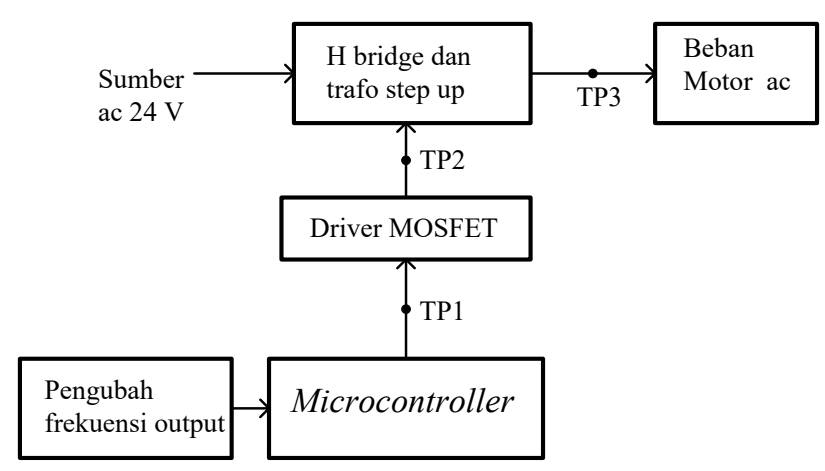

Gambar 7. Diagram blok rangkaian inverter

Pengubah frekuensi output menggunakan rotary encoder dengan cara memutar ke kanan untuk naik atau ke kiri untuk turun. Pemilihan komponen ini adalah untuk frekuensi default yang tidak tergantung dari posisi saklar pemilih saat awal perangkat dijalankan. Terdapat 5 pilihan frekuensi output yaitu, 30, 40, 50, 60 dan $70 \mathrm{~Hz}$. Frekuensi default adalah $50 \mathrm{~Hz}$.

\section{B. Pembangkitan SPWM Unipolar}

Pencacahan gelombang sinus menjadi pulsa-pulsa dengan lebar yang bervariasi dengan perioda tetap dilakukan dengan bantuan perangkat lunak dalam Atmega16. Untuk pencacahan 10 tiap setengah perioda dan frekuensi output 50 $\mathrm{Hz}$ akan menghasilkan frekuensi pulsa sebesar $1 \mathrm{k} \mathrm{Hz}$. Variasi lebar pulsa mewakili amplitudo gelombang sinus. Amplitudo tiap cacahan dapat dihitung berdasar sudut dari masingmasing cacahan. Pada frekuensi $50 \mathrm{~Hz}$ dengan cacahan 10 dalam setengah perioda, maka beda sudut tiap cacahan adalah $18^{\circ}$. Amplitudo rata-rata tiap segment lengkung sinus dihitung dengan persamaan berikut,

$$
Y=\operatorname{Sin}\left(\frac{X}{180^{\circ}}\right) \pi
$$

Tabel 1 Hasil Pencacahan Setengah Perioda Sinus

\begin{tabular}{|c|c|l|}
\hline No & $X\left(^{\circ}\right)$ & $\operatorname{Sin}\left(X / 180^{\circ}\right) \pi$ atau $D$ \\
\hline 1 & 9 & 0,15643 \\
\hline 2 & 27 & 0,45399 \\
\hline 3 & 45 & 0,70710 \\
\hline 4 & 63 & 0,89100 \\
\hline 5 & 81 & 0,98768 \\
\hline 6 & 99 & 0,98768 \\
\hline 7 & 117 & 0,89100 \\
\hline 8 & 135 & 0,70710 \\
\hline 9 & 153 & 0,45399 \\
\hline 10 & 171 & 0,15643 \\
\hline
\end{tabular}

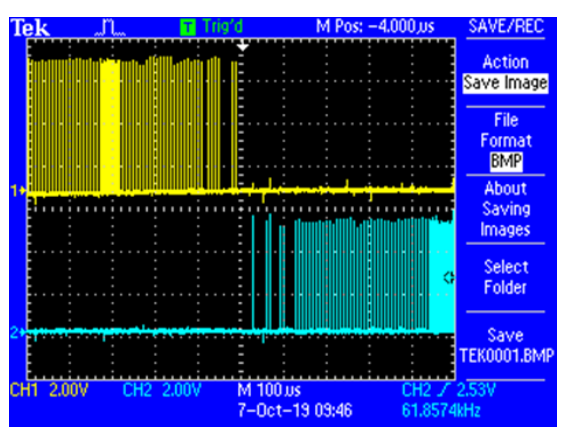

Gambar 8. Bentuk gelombang hasil pemrograman

Dengan $X$ adalah sudut cacahan, maka variasi duty cycle (D) dalam setengah perioda dapat dituliskan dalam Tabel 1. Bentuk gelombang SPWM hasil pemrograman ditunjukkan 
dalam Gambar 8.

\section{Rangkaian H bridge MOSFET Kanal $N$}

Skema rangkaian $H$ bridge MOSFET kanal $\mathrm{N}$ dan hubungannya dengan rangkaian penggerak ditunjukkan dalam Gambar 8. Dua buah penggerak MOSFET digabung jalur inputnya. HIN $U_{1}$ digabung dengan LIN $U_{2}$ sebagai saluran input 1 atau $V_{\mathrm{IN} 1}$ sehingga saat inverter bekerja dalam setengah perioda positip atau $V_{\mathrm{IN} 1}$ tinggi, $Q_{1}$ dan $Q_{4}$ hantar sedangkan pada saat $V_{\mathrm{IN} 2}$ tinggi, $Q_{2}$ dan $Q_{3}$ hantar dan gelombang output dalam setengah perioda negatip.

Tundaan waktu hantar sisi naik pulsa atau dead time atau delay matching diperlukan untuk menghindari terjadinya hubung singkat saklar segaris (shootthrough). Tundaan tersebut sudah menjadi fitur dari penggerak MOSFET IR2110. Berdasar lembar data, delay matching adalah 10 ns.[4]

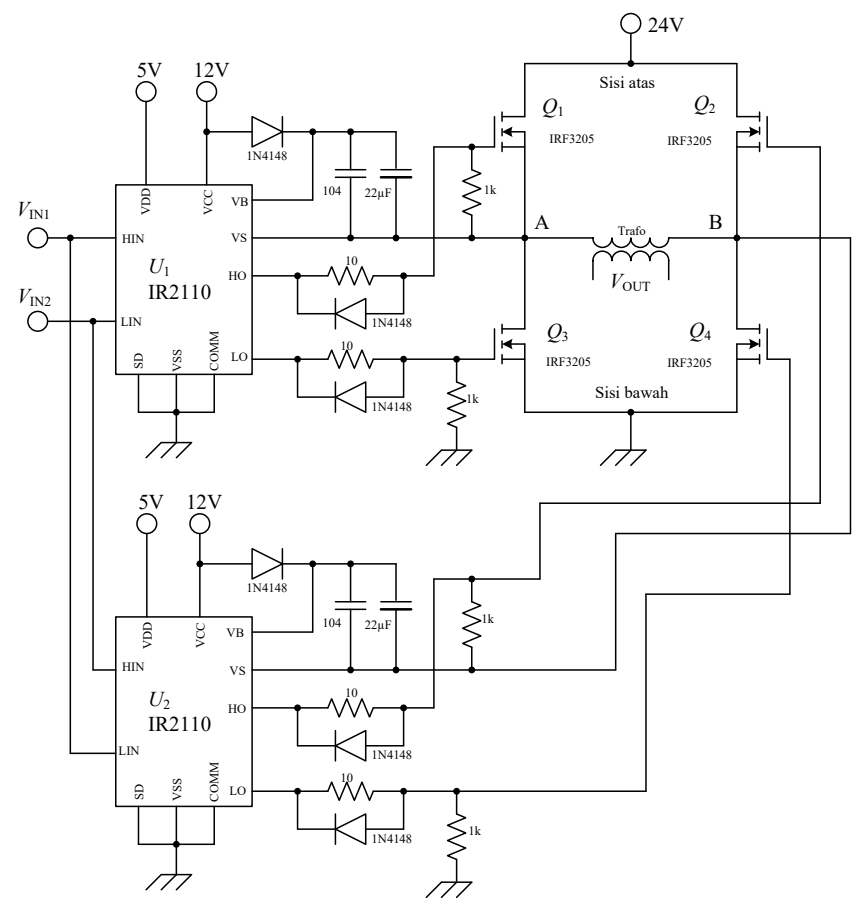

Gambar 9. Diagram blok rangkaian inverter

\section{Pembahasan}

\section{A. Hasil}

Pengamatan bentuk gelombang output untuk mengetahui frekuensi dan tegangan dilakukan dengan oscilloscope. Bentuk gelombang pada frekuensi 30 dan $50 \mathrm{~Hz}$ ditunjukkan dalam Gambar 9.

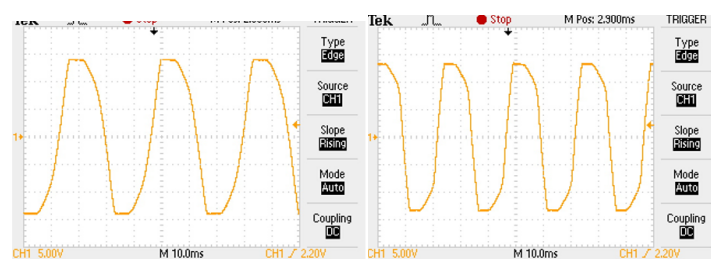

Gambar 10. Bentuk gelombang hasil pemrograman

Tegangan efektip output tidak sama saat tanpa beban dan dengan beban motor kipas 30 watt. Pengukuran dengan voltmeter digital. Tegangan tanpa beban adalah 225 volt sedangkan berbeban adalah 115 volt.

Dengan keping pendingin bersirip dari bahan aluminium yang di-anodizing, ukuran $3 \times 4 \mathrm{~cm}$, suhu MOSFET masih cuup tinggi dengan pengukuran tangan. Suhu MOSFET dpengaruhi oleh suhu lingkungan, dissipasi daya dan hambatan dalam. Jenis MOSFET ang dunakan adalah IRF3205 dengan hambatan dalam $R_{\mathrm{DS}(\mathrm{on})}$ ideal $=8 \mathrm{~m} \Omega$. [6]

\section{B. Pembahasan}

Berdasar data pengujian di atas terlihat bahwa bentuk gelombang sinus tidak sempurna atau cacat. Kemungkinan terjadinya cacat adalah kurang rapatnya jumlah cacahan pada SPWM atau juga dari beban yang bersifat indutip.

Stabilisasi tegangan output dapat dlakukan pada jalur dc input dengan umpan-balik dari tegangan output. Pengaturan dapat dilakukan secara linier maupun switching dengan konverter.

\section{KESIMPULAN DAN SARAN}

\section{A. Kesimpulan}

Penggunaan gelombang SPWM jenis unipolar pada inverter $\mathrm{H}$ bridge memudahan pengaturan frekuensi output. Kemampuan dissipasi daya saklar MOSFET dan hambatan dalamnya atau $R_{\mathrm{DS}(\mathrm{on}) \text {. Nilai hambatan tersebut juga }}$ dipengaruhi oleh suhu lingkungan sehingga pada kenyataannya tetap tidak bisa serendah nilai idealnya.

\section{B. Saran}

Pengaturan frekuensi secara manual pada penelitian ini adalah untuk tambahan modul praktikum Elektronika Daya terutama pada topik Inverter. Pemahaman tentang pembentukan gelombang SPWM secara program perlu ditambahkan lagi persamaan umum yang dapat diatur melalui kontrol sehingga dapat diamati perlakuan output secara otomatis.

Perlu dicoba rangkaian $H$ Bridge dengan konfigurasi seragam, CS atau dengan kanal yang berbalikan (komplemen). Rangkaian driver untuk konfigurasi CS seragam menjadi berbeda dan diperlukan perhtungan yang cermat terutama pada tegangan catu utama yang tinggi

\section{DAfTAR Pustaka}

[1] Anuja Naboodiri, Harshal S Wani, Unipolar and Bipolar SPWM Inverter, International Journal for Innovative Research in Science and Technology, Volume I December 2014

[2] Andras Tantos, H Bridge Drivers, modularcircuits.com. Unduh Sept. 2017

[3] Yohan Fajar Sidk, F Danang Wijaya dan Eka Frmansyah, Sinusoidal Pulse Width Modulation berbasis Lookup Table Untuk Inverter 1 Fase Menggunakan 16-bit Digital Signal Controller, Jurnal Nasional Teknik Elektro dan Teknologi Informasi (JNTETI), 2016.

[4] ATmega16A datasheet Atmel Corporation Available: http:// www.atmel.com. Unduh November 2015

[5] High and Low Side Driver IR2110 Datasheet, International Rectifier, www.irf.com Unduh Sept 2018

[6] Power MOSFET IRF3205 datasheet International Rectifier http://www.irf.com/package/ Unduh November 2017 